\title{
Nuclear Magnetic Resonance Studies of $\mathrm{BH}_{4}$ Reorientations and $\mathrm{Li}$ Diffusion in $\mathrm{LiLa}\left(\mathrm{BH}_{4}\right)_{3} \mathrm{Cl}$
}

\author{
Alexander V. Skripov, ${ }^{* \dagger}{ }^{\dagger}$ Alexei V. Soloninin, ${ }^{\dagger}$ Morten B. Ley, ${ }^{\ddagger}$ Torben R. Jensen, ${ }^{\ddagger}$ and Yaroslav Filinchuk ${ }^{\S}$ \\ ${ }^{\dagger}$ Institute of Metal Physics, Ural Division of the Russian Academy of Sciences, S. Kovalevskoi 18, Ekaterinburg 620990, Russia \\ ${ }^{\ddagger}$ Center for Materials Crystallography, Interdisciplinary Nanoscience Center and Department of Chemistry, Aarhus University, \\ Langelandsgade 140, 8000 Aarhus C, Denmark \\ ${ }^{\S}$ Institute of Condensed Matter and Nanosciences, Université Catolique de Louvain, Place L. Pasteur 1, 1348 Louvain-la-Neuve, \\ Belgium
}

\section{Supporting Information}

ABSTRACT: To study the reorientational motion of $\mathrm{BH}_{4}$ groups and the translational diffusion of $\mathrm{Li}^{+}$ions in the novel bimetallic borohydride chloride $\mathrm{LiLa}\left(\mathrm{BH}_{4}\right)_{3} \mathrm{Cl}$, we have measured the ${ }^{1} \mathrm{H},{ }^{11} \mathrm{~B}$, and ${ }^{7} \mathrm{Li}$ NMR spectra and spin-lattice relaxation rates in this compound over the temperature range of $23-418 \mathrm{~K}$. At low temperatures $(T<110 \mathrm{~K})$, the proton spinlattice relaxation rates are governed by fast reorientations of $\mathrm{BH}_{4}$ groups. This reorientational process can be satisfactorily described in terms of a two-peak distribution of the activation energies with the peak $E_{\mathrm{a}}$ values of 41 and $50 \mathrm{meV}$. Above $200 \mathrm{~K}$, the NMR data are governed by a combined effect of two types of motion occurring at the same frequency scale: $\mathrm{Li}$ ion diffusion and another (slower) reorientational motion of $\mathrm{BH}_{4}$ groups. These results suggest that the $\mathrm{Li}$ ion jumps and the slower reorientational jumps of $\mathrm{BH}_{4}$ groups in $\mathrm{LiLa}\left(\mathrm{BH}_{4}\right)_{3} \mathrm{Cl}$ may be correlated. The estimate of the tracer $\mathrm{Li}$ ion diffusion coefficient at room temperature $\left(5.2 \times 10^{-8} \mathrm{~cm}^{2} / \mathrm{s}\right)$ following from our experimental data indicates that $\mathrm{LiLa}\left(\mathrm{BH}_{4}\right)_{3} \mathrm{Cl}$ can be considered as a promising solid-state ionic conductor.

\section{INTRODUCTION}

Development of new sustainable and environment-friendly energy systems requires safe and efficient ways of energy storage. Renewable energy can be stored directly as electricity in batteries or indirectly as hydrogen in solid-state hydrides. ${ }^{1}$ Metal borohydrides have received recent attention as promising hydrogen-storage materials ${ }^{2-4}$ due to their high hydrogen densities. However, practical use of the known metal borohydrides is hindered by their stability with respect to thermal decomposition and the slow hydrogen sorption kinetics. $^{2-6}$ A number of methods (such as mechanical alloying, nanoconfinement, using catalytic additives) have been suggested $^{7-12}$ to destabilize borohydrides and make the kinetics of dehydrogenation and rehydrogenation more favorable. Recently, several bimetallic borohydrides and bimetallic borohydride chlorides have been synthesized, including $\mathrm{LiSc}$ $\left(\mathrm{BH}_{4}\right)_{4},{ }^{13,14} \mathrm{NaSc}\left(\mathrm{BH}_{4}\right)_{4},{ }^{15} \mathrm{KSc}\left(\mathrm{BH}_{4}\right)_{4},{ }^{16} \mathrm{KY}\left(\mathrm{BH}_{4}\right)_{4},{ }^{19} \mathrm{NaY}$ $\left(\mathrm{BH}_{4}\right)_{2} \mathrm{Cl}_{2},{ }^{18} \mathrm{LiCe}\left(\mathrm{BH}_{4}\right)_{3} \mathrm{Cl}^{19,20} \mathrm{LiLa}\left(\mathrm{BH}_{4}\right)_{3} \mathrm{Cl}^{21}$ and LiGd$\left(\mathrm{BH}_{4}\right)_{3} \mathrm{Cl}^{21}$ Some of these novel compounds are found to have very unusual crystal structures and relatively low decomposition temperatures (e.g., $\sim 260-280{ }^{\circ} \mathrm{C}$ for $\mathrm{LiCe}\left(\mathrm{BH}_{4}\right)_{3} \mathrm{Cl}$, well below the decomposition temperature for $\mathrm{LiBH}_{4}, \sim 380{ }^{\circ} \mathrm{C}$ ).

The bimetallic borohydride chloride $\mathrm{LiLa}\left(\mathrm{BH}_{4}\right)_{3} \mathrm{Cl}$ exhibits both high hydrogen density and high $\mathrm{Li}$ ion conductivity. ${ }^{21}$ Therefore, it can be considered both as a prospective hydrogenstorage material and an ionic conductor. In fact, the volumetric $\mathrm{H}$ density at room temperature for $\mathrm{LiLa}\left(\mathrm{BH}_{4}\right)_{3} \mathrm{Cl}\left(97.1 \mathrm{~kg} / \mathrm{m}^{3}\right)$ is comparable to the corresponding values for $\mathrm{LiBH}_{4}(123 \mathrm{~kg} /$ $\left.\mathrm{m}^{3}\right)$ and $\alpha-\mathrm{MgH}_{2}\left(108 \mathrm{~kg} / \mathrm{m}^{3}\right)$. The gravimetric $\mathrm{H}$ density in $\mathrm{LiLa}\left(\mathrm{BH}_{4}\right)_{3} \mathrm{Cl}$ is $5.36 \mathrm{wt} \%$. This should be compared to the corresponding values for $\mathrm{LiBH}_{4}\left(18.4 \mathrm{wt} \%\right.$ ) and $\mathrm{MgH}_{2}$ (7.6 wt $\%)$. The crystal structure of $\mathrm{LiLa}\left(\mathrm{BH}_{4}\right)_{3} \mathrm{Cl}$ is found to be cubic (space group $I \overline{4} 3 \mathrm{~m}$ ) with the unit cell parameter $a=11.7955$ $\AA_{;}^{21}$ this structure is isomorphous to that for $\mathrm{LiCe}\left(\mathrm{BH}_{4}\right)_{3} \mathrm{Cl}^{20}$ and $\mathrm{LiGd}\left(\mathrm{BH}_{4}\right)_{3} \mathrm{Cl}^{21}$ The structure contains isolated tetranuclear anionic clusters $\left[\mathrm{La}_{4} \mathrm{Cl}_{4}\left(\mathrm{BH}_{4}\right)_{12}\right]^{4-}$ with a distorted cubane $\mathrm{La}_{4} \mathrm{Cl}_{4}$ core, charge-balanced by $\mathrm{Li}^{+}$cations. Each $\mathrm{La}$ atom is coordinated by three $\mathrm{Cl}$ atoms and three $\mathrm{BH}_{4}$ groups via the $\mathrm{H}_{3}$ face, thus completing the coordination environment of an octahedron. $\mathrm{Li}^{+}$ions are disordered, occupying $2 / 3$ of the available $12 \mathrm{~d}$ sites. At $20{ }^{\circ} \mathrm{C}$ the measured $\mathrm{Li}$ ion conductivity of $\mathrm{LiLa}\left(\mathrm{BH}_{4}\right)_{3} \mathrm{Cl}$ is $2.3 \times 10^{-4} \mathrm{~S} / \mathrm{cm}^{21}$ Experimental studies of the relations between the crystal structure, $\mathrm{BH}_{4}$ rotational dynamics, and $\mathrm{Li}$ ion mobility are expected to contribute to the search for new materials with high ionic conductivity. Microscopic information on atomic motion can be obtained from nuclear magnetic resonance (NMR) and quasielastic neutron scattering (QENS) measurements. These techniques have been used in a series of recent studies of atomic motion in alkali, $^{22-33}$ alkaline-earth, ${ }^{34-39}$ and transition-metal borohydrides $^{40}$ and in $\mathrm{Li}\left(\mathrm{BH}_{4}\right)_{1-y} \mathrm{I}_{y}$ solid solutions. ${ }^{41-44}$ However, hydrogen dynamics and ion mobility in bimetallic borohydride-

Received: April 16, 2013

Revised: June 26, 2013

Published: July 1, 2013 
based systems have not been investigated so far. The aim of the present work is to study both the reorientational motion of $\mathrm{BH}_{4}$ groups and $\mathrm{Li}$ diffusion in $\mathrm{LiLa}\left(\mathrm{BH}_{4}\right)_{3} \mathrm{Cl}$ using ${ }^{1} \mathrm{H},{ }^{11} \mathrm{~B}$, and ${ }^{7} \mathrm{Li}$ NMR measurements of the spectra and spin-lattice relaxation rates over wide ranges of temperature $(23-418 \mathrm{~K})$ and resonance frequency $(14-90 \mathrm{MHz})$. We also discuss a possible relation between the reorientational motion and the translational diffusion in this compound. It is interesting to note that in a number of borohydride-based systems, such as the hightemperature (hexagonal) phase of $\mathrm{LiBH}_{4}$ and $\mathrm{LiBH}_{4}-\mathrm{LiI}$ solid solutions, the fast $\mathrm{Li}$ ion diffusion is accompanied by the very fast $\mathrm{BH}_{4}$ reorientations. ${ }^{29,42,43}$ However, in the systems studied so far, these two types of motion occur at different time scales. The results of the present work suggest that in $\mathrm{LiLa}\left(\mathrm{BH}_{4}\right)_{3} \mathrm{Cl}$ the diffusive $\mathrm{Li}$ ion jumps and a certain type of $\mathrm{BH}_{4}$ reorientations may be correlated since they occur at the same time scale.

\section{EXPERIMENTAL METHODS}

The sample preparation was analogous to that described in ref 21. All preparation and manipulation procedures were performed in a glovebox with a circulation purifier maintained under an argon atmosphere with less than $1 \mathrm{ppm}$ of $\mathrm{O}_{2}$ and $\mathrm{H}_{2} \mathrm{O}$. The $\mathrm{LaCl}_{3}-\mathrm{LiBH}_{4}$ mixture (1:3 molar ratio) was ballmilled in a Fritsch Pulverisette 4 planetary mill in an argon atmosphere using tungsten carbide balls and vial with 1:35 sample to balls mass ratio. To minimize sample heating, a $2 \mathrm{~min}$ milling period was followed by 2 min pause, and this procedure was repeated 60 times. The chemicals used were lanthanum chloride $\mathrm{LaCl}_{3}$ (Sigma-Aldrich, 99.9\%) and lithium borohydride $\mathrm{LiBH}_{4}$ (Sigma-Aldrich, 95\%). After the milling, the sample was annealed at $200{ }^{\circ} \mathrm{C}$ for 30 min under $\mathrm{H}_{2}$ (10 bar) atmosphere. According to $\mathrm{X}$-ray diffraction analysis, the resulting sample consisted of the cubic $\mathrm{LiLa}\left(\mathrm{BH}_{4}\right)_{3} \mathrm{Cl}$ (space group $\mathrm{I} 33 \mathrm{~m}, \mathrm{a}=$ 11.7955(1) $\AA$ ) and LiCl. For NMR experiments, the sample was flame-sealed in a glass tube under $\sim 500$ mbar of nitrogen gas.

NMR measurements were performed on a pulse spectrometer with quadrature phase detection at the frequencies $\omega / 2 \pi=$ 14, 28, and $90 \mathrm{MHz}$ for ${ }^{1} \mathrm{H}$ and $28 \mathrm{MHz}$ for both ${ }^{11} \mathrm{~B}$ and ${ }^{7} \mathrm{Li}$. The magnetic field was provided by a $2.1 \mathrm{~T}$ iron-core Bruker magnet. A home-built multinuclear continuous-wave NMR magnetometer working in the range $0.32-2.15 \mathrm{~T}$ was used for field stabilization. For rf pulse generation, we used a home-built computer-controlled pulse programmer, the PTS frequency synthesizer (Programmed Test Sources, Inc.), and a $1 \mathrm{~kW}$ Kalmus wide-band pulse amplifier. Typical values of the $\pi / 2$ pulse length were $2-3 \mu$ s for all nuclei studied. A probe head with the sample was placed into an Oxford Instruments CF1200 continuous-flow cryostat using helium or nitrogen as a cooling agent. The sample temperature in the range $23-418 \mathrm{~K}$, monitored by a chromel-( $\mathrm{Au}-\mathrm{Fe})$ thermocouple, was stable to $\pm 0.1 \mathrm{~K}$. The nuclear spin-lattice relaxation rates were measured using the saturation-recovery method. NMR spectra were recorded by Fourier transforming the solid echo signals (pulse sequence $\pi / 2_{x}-t-\pi / 2_{y}$ ).

\section{RESULTS AND DISCUSSION}

The behavior of the proton spin-lattice relaxation rates measured at three resonance frequencies for $\mathrm{LiLa}\left(\mathrm{BH}_{4}\right)_{3} \mathrm{Cl}$ is shown in Figure 1. As can be seen from this figure, the temperature dependences of the ${ }^{1} \mathrm{H}$ spin-lattice relaxation rate

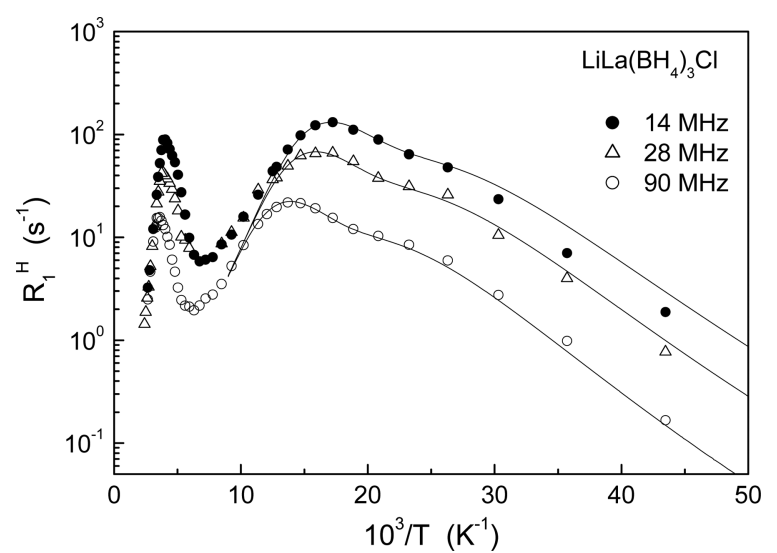

Figure 1. Proton spin-lattice relaxation rates measured at 14,28 , and $90 \mathrm{MHz}$ for $\mathrm{LiLa}\left(\mathrm{BH}_{4}\right)_{3} \mathrm{Cl}$ as functions of the inverse temperature. The experimental temperature range of the data is $23-418 \mathrm{~K}$. The solid lines show the simultaneous fit of the model with a two-peak distribution of the activation energies to the data in the range of the low-temperature $R_{1}^{\mathrm{H}}(T)$ peak.

$R_{1}^{\mathrm{H}}$ exhibit two peaks. Both peaks are frequency-dependent, which is typical of the relaxation mechanism due to the nuclear dipole-dipole interaction modulated by atomic motion. ${ }^{45}$ For this mechanism, the $R_{1}^{\mathrm{H}}(T)$ maximum is expected to occur at the temperature at which the atomic jump rate $\tau^{-1}$ becomes nearly equal to the resonance frequency $\omega$. On the basis of previous structural studies, ${ }^{20,21}$ we can conclude that LiLa$\left(\mathrm{BH}_{4}\right)_{3} \mathrm{Cl}$ has no polymorphic transitions in the temperature range investigated here. Thus, the presence of two wellseparated $R_{1}^{\mathrm{H}}(T)$ peaks indicates a coexistence of at least two types of atomic motion with strongly differing characteristic jump rates. The amplitude of each of the peaks is determined by the strength of the corresponding fluctuating part of the dipole-dipole interaction. For the borohydrides studied previously, the large $R_{1}^{\mathrm{H}}(T)$ peaks were found to originate from reorientational motion of $\mathrm{BH}_{4}$ groups, ${ }^{23,26,31,33,34,36,38-40,43}$ while smaller high-temperature $R_{1}^{\mathrm{H}}(T)$ peaks observed in some of them ${ }^{24,25,43}$ were attributed to slower translational motion of $\mathrm{Li}$ ions.

Low-Temperature Region. We shall start our analysis with a discussion of the behavior of the proton spin-lattice relaxation rates in the region of the low-temperature peak. For $\mathrm{LiLa}\left(\mathrm{BH}_{4}\right)_{3} \mathrm{Cl}$, this behavior resembles that found for $\mathrm{Li}$ $\left(\mathrm{BH}_{4}\right)_{1-y} \mathrm{I}_{y}$ solid solutions. ${ }^{43}$ In both cases, the proton relaxation rate maximum is observed below $80 \mathrm{~K}$; this indicates that the atomic motion responsible for the $R_{1}^{\mathrm{H}}(T)$ maximum is very fast. In fact, the $R_{1}^{H}(T)$ maximum for $\operatorname{LiLa}\left(\mathrm{BH}_{4}\right)_{3} \mathrm{Cl}$ at $\omega /$ $2 \pi=14 \mathrm{MHz}$ is observed near $58 \mathrm{~K}$, i.e., the jump rate $\tau^{-1}$ reaches the value of $\omega \sim 10^{8} \mathrm{~s}^{-1}$ already at this temperature. Comparing the $R_{1}^{\mathrm{H}}(T)$ data for $\mathrm{LiLa}\left(\mathrm{BH}_{4}\right)_{3} \mathrm{Cl}$ with those for other borohydride-based systems, we can conclude that the low-temperature proton relaxation rate peak originates from the reorientational motion of $\mathrm{BH}_{4}$ groups. As it will be discussed below, this conclusion is consistent with the behavior of the ${ }^{1} \mathrm{H}$ NMR line width. To estimate the relative strength of the ${ }^{1} \mathrm{H}-{ }^{11} \mathrm{~B},{ }^{1} \mathrm{H}-{ }^{1} \mathrm{H},{ }^{1} \mathrm{H}-{ }^{7} \mathrm{Li},{ }^{1} \mathrm{H}-{ }^{139} \mathrm{La}$, and ${ }^{1} \mathrm{H}-{ }^{35} \mathrm{Cl}$ dipoledipole interactions, we have calculated the corresponding contributions to the "rigid lattice" second moment of the ${ }^{1} \mathrm{H}$ NMR line on the basis of the structural data ${ }^{20,21}$ for $\mathrm{LiLa}\left(\mathrm{BH}_{4}\right)_{3} \mathrm{Cl}$ taking into account internuclear distances of up to $4 \AA$. The resulting rigid lattice contributions are $M_{\mathrm{HB}}^{\mathrm{R}}=$ 
$1.66 \times 10^{10} \mathrm{~s}^{-2}, M_{\mathrm{HH}}^{\mathrm{R}}=1.77 \times 10^{10} \mathrm{~s}^{-2}, M_{\mathrm{HLi}}^{\mathrm{R}}=5.7 \times 10^{8} \mathrm{~s}^{-2}$, $M_{\mathrm{HLa}}^{\mathrm{R}}=1.5 \times 10^{8} \mathrm{~s}^{-1}$, and $M_{\mathrm{HCl}}^{\mathrm{R}}=3.4 \times 10^{6} \mathrm{~s}^{-2}$. Thus, the dominant contributions originate from the $\mathrm{H}-\mathrm{B}$ and $\mathrm{H}-\mathrm{H}$ interactions, while the contributions of other dipole-dipole interactions can be neglected.

According to the standard theory ${ }^{45}$ of nuclear spin-lattice relaxation due to atomic motion, in the limit of slow motion $(\omega \tau \gg 1), R_{1}^{\mathrm{H}}$ should be proportional to $\omega^{-2} \tau^{-1}$, and in the limit of fast motion $(\omega \tau \ll 1), R_{1}^{\mathrm{H}}$ should be proportional to $\tau$ being frequency-independent. If the temperature dependence of the jump rate $\tau^{-1}$ is governed by the Arrhenius law with the activation energy $E_{\mathrm{a}}$

$$
\tau^{-1}=\tau_{0}^{-1} \exp \left(-E_{\mathrm{a}} / k_{\mathrm{B}} T\right)
$$

a plot of $\ln R_{1}^{\mathrm{H}}$ vs $T^{-1}$ should be linear in the limits of both slow and fast motion with the slopes $-E_{\mathrm{a}} / k_{\mathrm{B}}$ and $E_{\mathrm{a}} / k_{\mathrm{B}}$, respectively. As can be seen from Figure 1, the behavior of the measured proton spin-lattice relaxation rate in the region of the low-temperature peak deviates significantly from this simple picture. First, the observed high-temperature slope of the log $R_{1}^{\mathrm{H}}$ vs $T^{-1}$ plot is considerably steeper than the lowtemperature slope. Second, the experimental frequency dependence of $R_{1}^{\mathrm{H}}$ at the low-temperature slope is much weaker than the expected $\omega^{-2}$ dependence. These features are consistent with the presence of a broad distribution of $\mathrm{H}$ jump rates. ${ }^{46}$ Such a distribution in $\mathrm{LiLa}\left(\mathrm{BH}_{4}\right)_{3} \mathrm{Cl}$ can be expected, since $\mathrm{Li}$ ions in this compound randomly occupy $2 / 3$ of $12 \mathrm{~d}$ sites, so that the local environment of $\mathrm{a}_{4}$ group changes from one group to another. For disordered solids, the simplest approach to the description of a jump rate distribution is based on the model with a Gaussian distribution of the activation energies. Furthermore, the relaxation data shown in Figure 1 exhibit a "shoulder" near $45 \mathrm{~K}$; this suggests a coexistence of at least two low-temperature processes with different average jump rates. Therefore, for the description of the low-temperature $R_{1}^{\mathrm{H}}$ data we will use the two-peak model where the subscript $i(i=1,2)$ denotes the two jump processes, and $i=1$ corresponds to the faster motion. For this model

$$
R_{1}^{\mathrm{H}}=R_{11}^{\mathrm{H}}+R_{12}^{\mathrm{H}}
$$

where $R_{1 i}^{\mathrm{H}}$ is expressed as ${ }^{46}$

$$
R_{1 i}^{\mathrm{H}}=\int R_{1 i}^{\mathrm{H}}\left(E_{\mathrm{a} i}\right) G\left(E_{\mathrm{a} i}, \bar{E}_{\mathrm{a} i}, \Delta E_{\mathrm{a} i}\right) \mathrm{d} E_{\mathrm{a} i}
$$

Here $G\left(E_{\mathrm{a} i}, \bar{E}_{\mathrm{a} i}, \Delta E_{\mathrm{a} i}\right)$ is a Gaussian distribution function centered at $\bar{E}_{\mathrm{a} i}$ with the dispersion $\Delta E_{\mathrm{a} i}$ and $R_{1 i}^{\mathrm{H}}\left(E_{\mathrm{a} i}\right)$ is given by the standard theory ${ }^{45}$

$$
\begin{aligned}
R_{1 i}^{\mathrm{H}}\left(E_{\mathrm{a} i}\right)= & \frac{\Delta M_{\mathrm{HB} i} \tau_{i}}{2}\left[\frac{1}{1+\left(\omega_{\mathrm{H}}-\omega_{\mathrm{B}}\right)^{2} \tau_{i}^{2}}+\frac{3}{1+\omega_{\mathrm{H}}^{2} \tau_{i}^{2}}\right. \\
& \left.+\frac{6}{1+\left(\omega_{\mathrm{H}}+\omega_{\mathrm{B}}\right)^{2} \tau_{i}^{2}}\right]+\frac{4 \Delta M_{\mathrm{HH} i} \tau_{i}}{3} \\
& {\left[\frac{1}{4+\omega_{\mathrm{H}}^{2} \tau_{i}^{2}}+\frac{1}{1+\omega_{\mathrm{H}}^{2} \tau_{i}^{2}}\right] }
\end{aligned}
$$

where the equation analogous to eq 1 relates the jump rates $\tau_{i}^{-1}$ and the corresponding activation energies $E_{\mathrm{a} i}, \omega_{\mathrm{H}}$ and $\omega_{\mathrm{B}}$ are the resonance frequencies of ${ }^{1} \mathrm{H}$ and ${ }^{11} \mathrm{~B}$, respectively, and $\Delta M_{\mathrm{HBi}}$ and $\Delta M_{\mathrm{HH} i}$ are the parts of the dipolar second moment due to ${ }^{1} \mathrm{H}-{ }^{11} \mathrm{~B}$ and ${ }^{1} \mathrm{H}-{ }^{1} \mathrm{H}$ interactions that are caused to fluctuate by the $i$ th type of reorientational motion. It should be noted that usually the equations similar to eq 4 are written in terms of correlation times $\tau_{\mathcal{c}}$ not in terms of the residence times $\tau_{i}$. However, the relation between $\tau_{\mathrm{c}}$ and $\tau_{i}$ may differ for different interacting nuclear spins. When one of the interacting spins is immobile, $\tau_{\mathrm{c}}=\tau_{i}$, while for independently moving spins, $\tau_{\mathrm{c}}=\tau_{i} / 2$. A somewhat unusual form of the $\mathrm{H}-\mathrm{H}$ term in eq 4 originates from the fact that here we have explicitly assumed that $\tau_{\mathrm{c}}=\tau_{i} / 2$, which is true for most of the $\mathrm{H}-\mathrm{H}$ interactions in our system. The parameters of the model are $\Delta M_{\mathrm{HB} i}, \Delta M_{\mathrm{HH} i}$ $\tau_{0 i}, \bar{E}_{\mathrm{ai}}$, and $\Delta E_{\mathrm{a} i}$. These parameters can be varied to find the best fit to the $R_{1}^{\mathrm{H}}(T)$ data at the three resonance frequencies simultaneously. Since the $\mathrm{H}-\mathrm{B}$ and $\mathrm{H}-\mathrm{H}$ terms in eq 4 show nearly the same temperature and frequency dependences, it is practically impossible to determine the amplitude parameters $\Delta M_{\mathrm{HB} i}$ and $\Delta M_{\mathrm{HH} i}$ independently from the fits. The above estimates of the corresponding rigid lattice $\mathrm{H}-\mathrm{B}$ and $\mathrm{H}-\mathrm{H}$ contributions suggest that $\Delta M_{\mathrm{HB} i}$ and $\Delta M_{\mathrm{HH} i}$ are close to each other. Therefore, for parametrization of the $R_{1}^{\mathrm{H}}$ data we will assume that $\Delta M_{\mathrm{HBi}}=\Delta M_{\mathrm{HH} i} \equiv \Delta M_{i}$. The results of the simultaneous fit of the two-peak model (eqs 2, 3, 4 and the analogue of eq 1) to the experimental data in the range 23-110 $\mathrm{K}$ are shown by solid curves in Figure 1. As can be seen from this figure, the experimental data at three resonance frequencies are satisfactorily described by a single set of parameters. The values of the amplitude parameters resulting from this fit are $\Delta M_{1}=2.3 \times 10^{9} \mathrm{~s}^{-2}$ and $\Delta M_{2}=5.1 \times 10^{9} \mathrm{~s}^{-2}$, and the corresponding motional parameters are $\tau_{01}=(5.1 \pm 0.9) \times$ $10^{-14} \mathrm{~s}, \bar{E}_{\mathrm{a} 1}=41 \pm 5 \mathrm{meV}, \Delta E_{\mathrm{a} 1}=7 \pm 2 \mathrm{meV}$, and $\tau_{02}=(5.5 \pm$ $0.8) \times 10^{-13} \mathrm{~s}, \bar{E}_{\mathrm{a} 2}=50 \pm 3 \mathrm{meV}, \Delta E_{\mathrm{a} 2}=6 \pm 2 \mathrm{meV}$. It should be noted that the values of $\bar{E}_{\mathrm{a} 1}$ and $\bar{E}_{\mathrm{a} 2}$ for $\mathrm{LiLa}\left(\mathrm{BH}_{4}\right)_{3} \mathrm{Cl}$ are close to the activation energies for the faster reorientational process in $\mathrm{LiBH}_{4}-\mathrm{LiI}$ solid solutions. ${ }^{43}$

The local environment of the $\mathrm{BH}_{4}$ group in $\mathrm{LiLa}\left(\mathrm{BH}_{4}\right)_{3} \mathrm{Cl}$ is schematically shown in Figure 2. The $\mathrm{BH}_{4}$ tetrahedron is

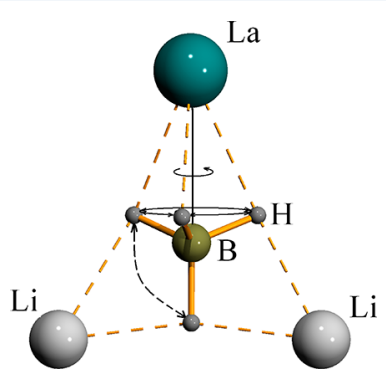

Figure 2. Schematic view of the coordination environment of a $\mathrm{BH}_{4}$ group in $\mathrm{LiLa}\left(\mathrm{BH}_{4}\right)_{3} \mathrm{Cl}$. The $\mathrm{B}-\mathrm{H}$ bonds are shown by yellow bars, and the $\mathrm{La}-\mathrm{H}$ and $\mathrm{Li}-\mathrm{H}$ bonds are shown by dashed yellow lines. Only two of three nearest-neighbor Li sites are shown; since two-thirds of the available $\mathrm{Li}$ sites are randomly occupied by $\mathrm{Li}$ ions, this corresponds to the most probable configuration. The local threefold axis of the $\mathrm{BH}_{4}$ group is oriented vertically. The solid black lines with arrows show the proposed fast reorientational process, and the dashed black line with arrows is associated with the slower exchange process.

coordinated by a single $\mathrm{La}$ atom via the face and by three $\mathrm{Li}$ sites via the edges. However, only two-thirds of the available $\mathrm{Li}$ sites are randomly occupied by $\mathrm{Li}$ ions. Figure 2 corresponds to the most probable configuration with two nearest-neighbor $\mathrm{Li}$ ions, but it should be kept in mind that the actual number of the nearest-neighbor $\mathrm{Li}$ ions may vary from one $\mathrm{BH}_{4}$ group to another. This local environment suggests that the most probable "easy" reorientation axis is the threefold axis directed along the $\mathrm{La}-\mathrm{B}$ line. In fact, the rotation of the $\mathrm{BH}_{4}$ group 
around this threefold axis does not break any $\mathrm{La}-\mathrm{H}$ bonds, and, since the apical $\mathrm{H}$ atom does not move, it breaks only one-half of the $\mathrm{Li}-\mathrm{H}$ bonds. While the low values of $\bar{E}_{\mathrm{a} 1}$ and $\bar{E}_{\mathrm{a} 2}$ indicate that the $\mathrm{Li}-\mathrm{H}$ bonds are weak, the motion of $\mathrm{BH}_{4}$ groups in $\mathrm{LiLa}\left(\mathrm{BH}_{4}\right)_{3} \mathrm{Cl}$ around the threefold axes cannot be considered as a "free" rotation. In fact, neutron diffraction measurements ${ }^{20}$ for the related $\mathrm{LiCe}\left(\mathrm{BD}_{4}\right)_{3} \mathrm{Cl}$ compound have not revealed any anomalously large displacements of $\mathrm{D}$ atoms from their crystallographic sites. It seems reasonable to assume that the two jump processes contributing to the low-temperature $R_{1}^{\mathrm{H}}(T)$ peak correspond to the threefold reorientations of $\mathrm{BH}_{4}$ groups having two or one nearest-neighbor $\mathrm{Li}$ ions; the former case should then be ascribed to the slower process, and the latter one to the faster process.

Figure 3 shows the temperature dependence of the ${ }^{1} \mathrm{H}$ NMR line width $\Delta \nu_{\mathrm{H}}$ (full width at half-maximum) measured at 28

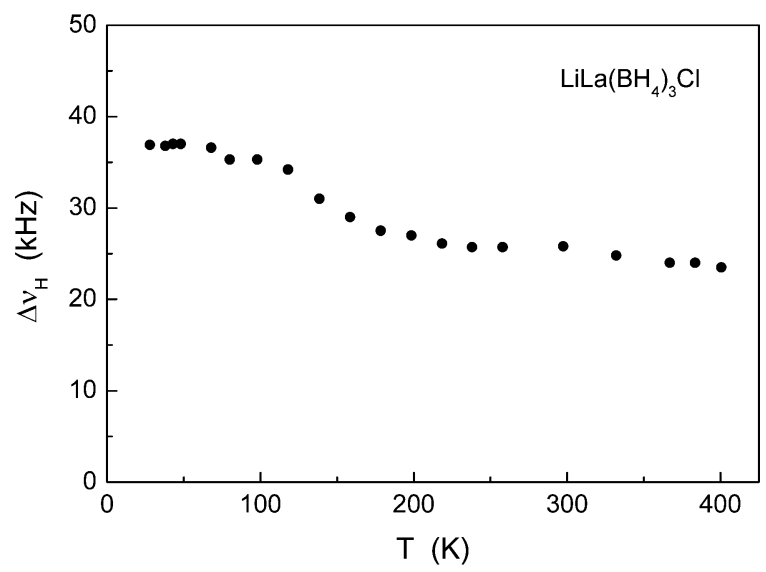

Figure 3. Temperature dependence of the width (full width at halfmaximum) of the ${ }^{1} \mathrm{H}$ NMR line measured at $28 \mathrm{MHz}$ for $\mathrm{LiLa}\left(\mathrm{BH}_{4}\right)_{3} \mathrm{Cl}$.

$\mathrm{MHz}$. In the range $28-100 \mathrm{~K}$, the line width remains nearly constant. However, the value of $\Delta \nu_{\mathrm{H}}$ in this range $(\sim 36 \mathrm{kHz})$ appears to be considerably smaller than the expected line width for the rigid lattice $(\sim 70 \mathrm{kHz})$. This suggests that a partial line narrowing occurs even at temperatures as low as $28 \mathrm{~K}$. In agreement with the proton spin-lattice relaxation data, such a behavior of $\Delta \nu_{\mathrm{H}}$ indicates that the fast atomic motion in $\mathrm{LiLa}\left(\mathrm{BH}_{4}\right)_{3} \mathrm{Cl}$ survives down to very low temperatures. A substantial line narrowing is expected when the atomic jump rate $\tau^{-1}$ becomes nearly equal to the rigid lattice line width ${ }^{45}$ (in our case, this value is of the order of $10^{5} \mathrm{~s}^{-1}$ ). However, localized $\mathrm{H}$ motion (such as $\mathrm{BH}_{4}$ reorientations) leads to only partial averaging of the dipole-dipole interactions, so that $\Delta \nu_{\mathrm{H}}$ remains finite even at jump rates much higher than $10^{5} \mathrm{~s}^{-1}$. Thus, the $\Delta \nu_{\mathrm{H}}(T)$ plateau in the range $28-100 \mathrm{~K}$ (Figure 3) is consistent with the localized character of the low-temperature $\mathrm{H}$ jump motion. Similar plateaus in the temperature dependences of the proton NMR line widths were observed for other borohydrides showing $\mathrm{BH}_{4}$ reorientations. ${ }^{23-26,31,33,34,38}$ The value of $\Delta \nu_{\mathrm{H}}$ at the plateau is determined by the strength of dipole-dipole interactions, which are not averaged out by a particular type of localized motion. It should be noted that for $\mathrm{LiLa}\left(\mathrm{BH}_{4}\right)_{3} \mathrm{Cl}$ the value of $\Delta \nu_{\mathrm{H}}$ at the low-temperature plateau is larger than the corresponding values for other studied borohydrides. This means that the low-temperature reorientational motion in $\mathrm{LiLa}\left(\mathrm{BH}_{4}\right)_{3} \mathrm{Cl}$ averages out a relatively small fraction of the rigid lattice dipole-dipole interactions. Such a feature supports our assumption that the low-temperature reorientational motion in $\mathrm{LiLa}\left(\mathrm{BH}_{4}\right)_{3} \mathrm{Cl}$ corresponds to rotations around a single threefold axis, since this type of motion does not lead to complete averaging of the dipolar interactions even within the $\mathrm{BH}_{4}$ group. As can be seen from Figure 3 , at $T>130 \mathrm{~K}$ the proton line width decreases and reaches the new plateau. This behavior will be discussed in the next section.

High-Temperature Region. The expanded view of the $R_{1}^{\mathrm{H}}(T)$ data in the region of the high-temperature peak is shown in Figure 4. General features of the observed behavior of $R_{1}^{\mathrm{H}}(T)$

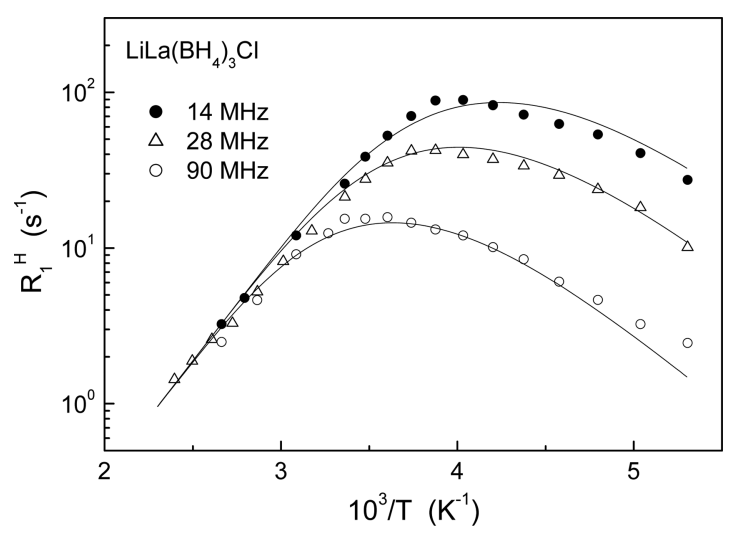

Figure 4. Proton spin-lattice relaxation rates measured at 14, 28, and $90 \mathrm{MHz}$ for $\mathrm{LiLa}\left(\mathrm{BH}_{4}\right)_{3} \mathrm{Cl}$ as functions of the inverse temperature in the range of the high-temperature $R_{1}^{\mathrm{H}}(T)$ peak. The data are shown in the temperature range $189-418 \mathrm{~K}$. The solid lines show the simultaneous fit of the model with a Gaussian distribution of the activation energies to the data.

in this range are typical of the peak originating from some kind of atomic motion. Can this peak result from the translational diffusion of $\mathrm{Li}$ ions? To answer this question, we first discuss the behavior of the ${ }^{7} \mathrm{Li}$ NMR line width, $\Delta \nu_{\mathrm{Li}}$.

Figure 5 shows the measured temperature dependence of the width of the central ${ }^{7} \mathrm{Li} \mathrm{NMR}$ line for $\mathrm{LiLa}\left(\mathrm{BH}_{4}\right)_{3} \mathrm{Cl}$. The observed strong narrowing of this line above $200 \mathrm{~K}$ is consistent with the onset of $\mathrm{Li}$ jump motion at the frequency scale of $\sim 10^{4} \mathrm{~s}^{-1}$. The value of $\Delta \nu_{\mathrm{Li}}$ in the region of the hightemperature plateau $(0.38 \mathrm{kHz})$ is considerably smaller than the expected line width $(\sim 1.4 \mathrm{kHz})$ for the ${ }^{7} \mathrm{Li}-{ }^{7} \mathrm{Li}$ dipolar

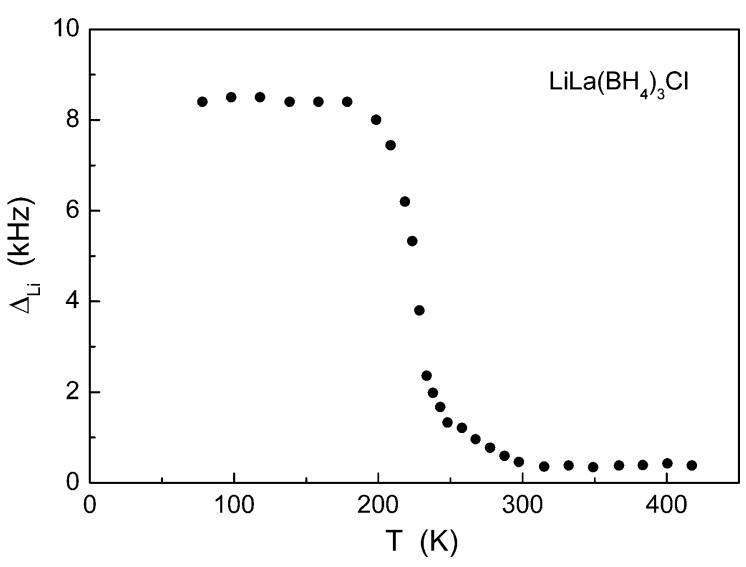

Figure 5. Temperature dependence of the width (full width at halfmaximum) of the central ${ }^{7} \mathrm{Li} \mathrm{NMR}$ line measured at $28 \mathrm{MHz}$ for $\mathrm{LiLa}\left(\mathrm{BH}_{4}\right)_{3} \mathrm{Cl}$. 
contribution to the rigid lattice second moment. Therefore, the ${ }^{7} \mathrm{Li}-{ }^{7} \mathrm{Li}$ dipole-dipole interaction is averaged out in the region of the high-temperature plateau; this can occur only in the case of long-range diffusion of $\mathrm{Li}$ ions. For the same motional process, the spin-lattice relaxation rate maximum is expected to appear at higher temperatures than the drop of the line width; thus, the position of the high-temperature $R_{1}^{\mathrm{H}}(T)$ peak $(\sim 250 \mathrm{~K}$ at $14 \mathrm{MHz})$ shows that this peak may originate from $\mathrm{Li}$ diffusion. However, as we shall see, the amplitude of this peak is too high to result solely from $\mathrm{Li}$ diffusion. Indeed, the estimate of the ${ }^{1} \mathrm{H}-{ }^{7} \mathrm{Li}$ contribution to the rigid-lattice dipolar second moment of the ${ }^{1} \mathrm{H}$ NMR line gives $5.7 \times 10^{8} \mathrm{~s}^{-2}$ (see above). The full modulation of this ${ }^{1} \mathrm{H}-{ }^{7} \mathrm{Li}$ interaction due to $\mathrm{Li}$ diffusion would result in the maximum $R_{1}^{\mathrm{H}}$ value of $15 \mathrm{~s}^{-1}$ at $14 \mathrm{MHz}$. The measured maximum $R_{1}^{\mathrm{H}}$ value for the hightemperature peak $\left(89 \mathrm{~s}^{-1}\right.$ at $\left.14 \mathrm{MHz}\right)$ is considerably higher than that estimated for the case of $\mathrm{Li}$ diffusion. Note that for the proton relaxation peak resulting solely from $\mathrm{Li}$ diffusion in the high-temperature phase of $\mathrm{LiBH}_{4}$ the maximum $R_{1}^{\mathrm{H}}$ value is $13.8 \mathrm{~s}^{-1}$ at $14 \mathrm{MHz}{ }^{25}$ Thus, we can conclude that the hightemperature $R_{1}^{\mathrm{H}}(T)$ peak in $\mathrm{LiLa}\left(\mathrm{BH}_{4}\right)_{3} \mathrm{Cl}$ originates from a combined effect of at least two motional processes occurring at the same frequency scale: $\mathrm{Li}$ ion diffusion and another process that involves $\mathrm{H}$ jumps. The latter process should give the dominant contribution to the amplitude of the high-temperature $R_{1}^{\mathrm{H}}(T)$ peak. Since the proton NMR line width $\Delta \nu_{\mathrm{H}}$ remains rather large up to $400 \mathrm{~K}$ (see Figure 3), we can exclude the possibility of long-range diffusion of $\mathrm{H}$-containing species in the studied temperature range. Therefore, the process involving $\mathrm{H}$ jumps should be attributed to some kind of $\mathrm{BH}_{4}$ reorientations. In the following, we will refer to it as the slower reorientational process; this means that its characteristic jump rate $\tau_{3}^{-1}(T)$ is several orders of magnitude lower than both $\tau_{1}^{-1}(T)$ and $\tau_{2}^{-1}(T)$ in the range of the high-temperature $R_{1}^{\mathrm{H}}(T)$ peak. Most probably, the slower reorientations are those leading to exchange between $\mathrm{H}$ atoms in the La-coordinated plane of the $\mathrm{BH}_{4}$ tetrahedron and the remaining apical $\mathrm{H}$ atom. On the basis of quasielastic neutron scattering measurements, ${ }^{32,44}$ such an exchange has been identified as the slower reorientational process in the high-temperature phase of $\mathrm{LiBH}_{4}$ and in the $\mathrm{LiBH}_{4}-\mathrm{LiI}$ solid solution. This process is schematically shown by the dashed line with arrows in Figure 2. The relevant physical picture ${ }^{32,44}$ implies that each $\mathrm{BH}_{4}$ group performs many reorientational jumps around the threefold axis before the occurrence of an exchange between one of the moving $\mathrm{H}$ atoms and the static apical $\mathrm{H}$ atom.

To the best of our knowledge, this is the first time that an ion diffusion and reorientational motion occurring at the same frequency scale are found in $\mathrm{BH}_{4}$-based systems. However, similar observations were reported for a number of orthophosphate-based ionic conductors, ${ }^{47-49}$ such as $\mathrm{Na}_{3} \mathrm{PO}_{4}$. For these compounds, there is a strong evidence of dynamic coupling between the anion rotation and cation diffusion, as discussed in terms of the "paddle-wheel" mechanism. ${ }^{47}$ It is likely that, in the case of $\mathrm{LiLa}\left(\mathrm{BH}_{4}\right)_{3} \mathrm{Cl}$, the slower $\mathrm{BH}_{4}$ reorientations and $\mathrm{Li}$ jumps may also be correlated. On the basis of our data, it is impossible to conclude unambiguously which type of motion (reorientations or $\mathrm{Li}$ jumps) is the primary driving force. However, in the framework of the paddle-wheel mechanism, ${ }^{47}$ the reorientational motion is believed to initiate cation jumps. In our case, one may also assume that a certain tumbling of the $\mathrm{BH}_{4}$ tetrahedron initiates a jump of the adjacent $\mathrm{Li}$ ion to the nearest-neighbor vacant site.

For parametrization of the proton spin-lattice relaxation results in the region of the high-temperature $R_{1}^{\mathrm{H}}(T)$ peak, we have used the simplest model that is consistent with general features of the data, i.e., the one-peak model with a Gaussian distribution of the activation energies. Since the high-temperature $R_{1}^{\mathrm{H}}(T)$ peak is dominated by slower reorientational process, we introduce the $\mathrm{H}$ jump rate $\tau_{3}^{-1}$ for this process with the corresponding pre-exponential factor $\tau_{03}^{-1}$, the average activation energy $\bar{E}_{\mathrm{a} 3}$, and the distribution width $\Delta E_{\mathrm{a} 3}$. The model is described by eqs 3 and 4 and the analogue of eq 1 . The results of the simultaneous fit of this model to the $R_{1}^{\mathrm{H}}(T)$ data at three resonance frequencies in the range $189-418 \mathrm{~K}$ are shown by solid lines in Figure 4. The motional parameters resulting from the fit are $\tau_{03}=(2.1 \pm 0.6) \times 10^{-14} \mathrm{~s}, \bar{E}_{\mathrm{a} 3}=264$ $\pm 8 \mathrm{meV}$, and $\Delta E_{\mathrm{a} 3}=31 \pm 5 \mathrm{meV}$. While this model satisfactorily describes the main features of the data over broad ranges of temperature and the resonance frequency, the fit is not perfect. This may be related to the fact that the model does not explicitly take into account the diffusive $\mathrm{Li}$ jumps, the mean rate of which, $\tau_{\mathrm{d}}^{-1}$, may not coincide exactly with $\tau_{3}^{-1}$.

The ${ }^{11} \mathrm{~B}$ and ${ }^{7} \mathrm{Li}$ spin-lattice relaxation measurements have been performed in the high-temperature region at the frequency of $28 \mathrm{MHz}$. For both nuclei, the recovery of the nuclear magnetization deviates from a single-exponential behavior, and the recovery curves can be reasonably approximated by a sum of two-exponential functions. For ${ }^{11} \mathrm{~B}$, the two-exponential relaxation was found in some borohydrides; ${ }^{36}$ such a behavior may be ascribed ${ }^{45}$ to nonzero electric quadrupole moment of this nucleus. For ${ }^{7} \mathrm{Li}$, an additional complication may arise from the presence of $\mathrm{LiCl}$ in our sample (see the Experimental Methods section). However, the ${ }^{7} \mathrm{Li}$ spin-lattice relaxation times for pure $\mathrm{LiCl}$ are very long; therefore, this additional phase is not expected to give any significant contributions on the time scale of our ${ }^{7} \mathrm{Li}$ NMR experiments. For both ${ }^{11} \mathrm{~B}$ and ${ }^{7} \mathrm{Li}$, the observed twoexponential recovery is dominated by the faster relaxation component $R_{1 \mathrm{~F}}$. The temperature dependences of the faster components of the ${ }^{11} \mathrm{~B}$ and ${ }^{7} \mathrm{Li}$ spin-lattice relaxation rates are shown in Figure 6. The behavior of $R_{1 \mathrm{~F}}$ for ${ }^{11} \mathrm{~B}$ resembles that of the ${ }^{1} \mathrm{H}$ spin-lattice relaxation rate in this range (Figure 4). As in the case of the ${ }^{1} \mathrm{H}$ relaxation, the maximum $R_{1 \mathrm{~F}}$ value for

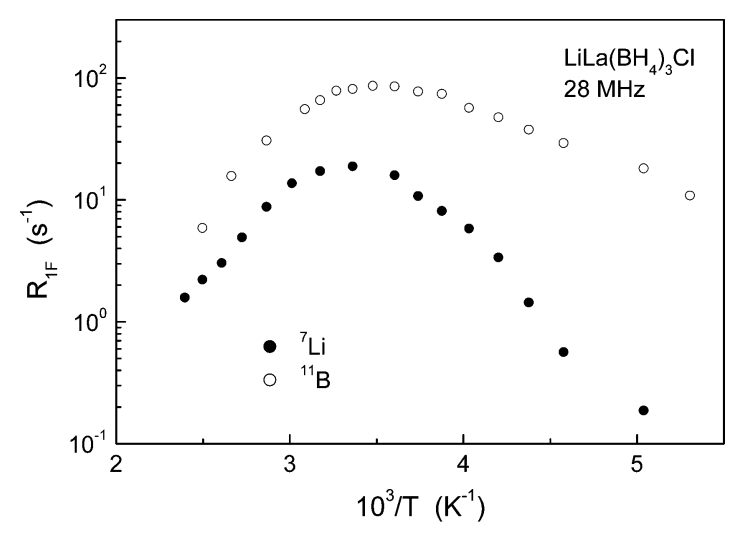

Figure 6. Fast components of the ${ }^{7} \mathrm{Li}$ and ${ }^{11} \mathrm{~B}$ spin-lattice relaxation rates measured at $28 \mathrm{MHz}$ for $\mathrm{LiLa}\left(\mathrm{BH}_{4}\right)_{3} \mathrm{Cl}$ as functions of the inverse temperature. The data are shown in the temperature range $189-418 \mathrm{~K}$ 
${ }^{11} \mathrm{~B}\left(\sim 86 \mathrm{~s}^{-1}\right)$ appears to be much larger than that resulting solely from $\mathrm{Li}$ diffusion. For comparison, the maximum ${ }^{11} \mathrm{~B}$ spin-lattice relaxation rate resulting from $\mathrm{Li}$ diffusion in the high-temperature phase of $\mathrm{LiBH}_{4}$ is $1.1 \mathrm{~s}^{-1}$ at $23.8 \mathrm{MHz}$. Thus, the observed peak of the ${ }^{11} \mathrm{~B}$ spin-lattice relaxation rate in $\mathrm{LiLa}\left(\mathrm{BH}_{4}\right)_{3} \mathrm{Cl}$ should be dominated by some reorientational process. For the ${ }^{7} \mathrm{Li}$ relaxation rate peak, the situation is more complex. Because of the relative weakness of the ${ }^{7} \mathrm{Li}-{ }^{1} \mathrm{H}$ dipole-dipole interactions, the effect of $\mathrm{BH}_{4}$ reorientations on the ${ }^{7} \mathrm{Li}$ relaxation rate is moderate, so that the maximum $R_{1 \mathrm{~F}}$ value for ${ }^{7} \mathrm{Li}\left(\sim 18.9 \mathrm{~s}^{-1}\right)$ is only a factor of $3-4$ larger than that expected for $\mathrm{Li}$ jumps alone. In fact, the maximum ${ }^{7} \mathrm{Li}$ spinlattice relaxation rate resulting from $\mathrm{Li}$ diffusion in the hightemperature phase of $\mathrm{LiBH}_{4}$ is $5.2 \mathrm{~s}^{-1}$ at $23.8 \mathrm{MHz}^{25}$ Therefore, the effects of $\mathrm{Li}$ jump motion should be more pronounced in the ${ }^{7} \mathrm{Li}$ relaxation results than in the ${ }^{1} \mathrm{H}$ and ${ }^{11} \mathrm{~B}$ relaxation data. It should also be noted that the $R_{1 \mathrm{~F}}$ maximum for ${ }^{7} \mathrm{Li}$ is shifted to somewhat higher temperature from the corresponding maxima for the ${ }^{1} \mathrm{H}$ and ${ }^{11} \mathrm{~B}$ relaxation rates. We have not tried to fit the ${ }^{11} \mathrm{~B}$ and ${ }^{7} \mathrm{Li}$ spin-lattice relaxation data in the region of the peak. However, a rough estimate of the activation energy $E_{\mathrm{a}}^{\mathrm{d}}$ for Li diffusion can be obtained using the high-temperature slope of the ${ }^{7} \mathrm{Li}$ spin-lattice relaxation rate peak. Such an estimate yields $E_{\mathrm{a}}^{\mathrm{d}} \approx 0.30 \mathrm{eV}$. This value is close to $\bar{E}_{\mathrm{a} 3}$ for the slower reorientational process in $\mathrm{LiLa}\left(\mathrm{BH}_{4}\right)_{3} \mathrm{Cl}$ (see above). For comparison, the activation energy for $\mathrm{Li}$ diffusion in the high-temperature phase of $\mathrm{LiBH}_{4}$ is considerably higher $\left(0.56 \mathrm{eV}^{22,25}\right.$ and $\left.0.54 \mathrm{eV}^{30}\right)$.

Our data show that the diffusive mobility of $\mathrm{Li}$ ions in $\mathrm{LiLa}\left(\mathrm{BH}_{4}\right)_{3} \mathrm{Cl}$ is very high. This is supported by the fact that the strong narrowing of the ${ }^{7} \mathrm{Li}$ NMR line occurs already at $T \approx$ $220 \mathrm{~K}$. For most of the studied solid Li ion conductors (such as $\mathrm{Li}_{3} \mathrm{~N}, \quad \mathrm{Li}_{x} \mathrm{TiS}_{2}, \mathrm{LiNbO}_{3}, \mathrm{Li}$ aluminosilicates $\left.{ }^{50,51}\right)$, the line narrowing is observed at higher temperatures. A rough estimate of the $\mathrm{Li}$ jump rate $\tau_{\mathrm{d}}^{-1}$ for $\mathrm{LiLa}\left(\mathrm{BH}_{4}\right)_{3} \mathrm{Cl}$ can be obtained at the temperature of the $R_{1}^{\mathrm{Li}}$ maximum $(\sim 297 \mathrm{~K}$ at $28 \mathrm{MHz})$. Such an estimate yields $\tau_{\mathrm{d}}^{-1}(297 \mathrm{~K}) \approx 1.8 \times 10^{8} \mathrm{~s}^{-1}$. The sublattice of $12 \mathrm{~d}$ sites partially occupied by $\mathrm{Li}$ ions in $\mathrm{LiLa}\left(\mathrm{BH}_{4}\right)_{3} \mathrm{Cl}$ is shown in Figure 7. It is interesting to note that this sublattice is

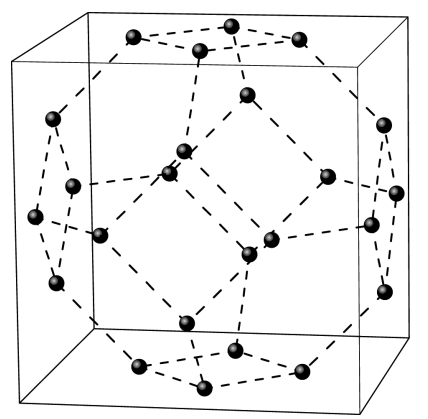

Figure 7. Sublattice of $12 \mathrm{~d}$ sites, two-thirds of which are randomly occupied by $\mathrm{Li}$ ions in $\mathrm{LiLa}\left(\mathrm{BH}_{4}\right)_{3} \mathrm{Cl}$. The dashed lines show possible diffusion paths within the unit cell.

isomorphous to the sublattice of tetrahedral interstitial sites in body-centered cubic metals, where $\mathrm{H}$ atoms partially occupying these sites show very high diffusive mobility. 52

The distance $L$ between the nearest-neighbor $12 \mathrm{~d}$ sites in $\mathrm{LiLa}\left(\mathrm{BH}_{4}\right)_{3} \mathrm{Cl}$ is $4.17 \AA$. Neglecting any correlations in jump motion, the tracer diffusion coefficient of $\mathrm{Li}$ ions can be estimated as $D(297 \mathrm{~K})=L^{2} \tau_{\mathrm{d}}^{-1}(297 \mathrm{~K}) / 6 \approx 5.2 \times 10^{-8} \mathrm{~cm}^{2} / \mathrm{s}$.
According to the data of ref 25 , for the high-temperature phase of $\mathrm{LiBH}_{4}$, the same value of $\mathrm{D}$ is reached at $420 \mathrm{~K}$, i.e., at much higher temperature. Note that, in contrast to the case of $\mathrm{LiBH}_{4}$, the sublattice of $\mathrm{Li}$ sites in $\mathrm{LiLa}\left(\mathrm{BH}_{4}\right)_{3} \mathrm{Cl}$ contains many vacancies. This factor is expected to facilitate $\mathrm{Li}$ ion diffusion. Following Matsuo et al., ${ }^{22}$ we can estimate the ionic conductivity $\sigma$ from the Nernst-Einstein equation

$$
\sigma=n D(Z e)^{2} / k_{\mathrm{B}} T
$$

where $n$ is the number of charge carriers per unit volume and $\mathrm{Ze}$ is the electrical charge of the carrier. Using the lattice parameter of $\mathrm{LiLa}\left(\mathrm{BH}_{4}\right)_{3} \mathrm{Cl}^{21}$ and taking into account that $\mathrm{Li}$ ions occupy two-thirds of the available $12 \mathrm{~d}$ sites, we find that $n$ $=4.88 \times 10^{21} \mathrm{~cm}^{-3}$ and $\sigma(297 \mathrm{~K}) \approx 2 \times 10^{-3} \mathrm{~S} / \mathrm{cm}$. This estimate shows that $\mathrm{LiLa}\left(\mathrm{BH}_{4}\right)_{3} \mathrm{Cl}$ has a potential to be among the best solid $\mathrm{Li}$ ion conductors. ${ }^{53}$ The measured roomtemperature conductivity of $\mathrm{LiLa}\left(\mathrm{BH}_{4}\right)_{3} \mathrm{Cl}\left(2.3 \times 10^{-4} \mathrm{~S} / \mathrm{cm}\right)^{21}$ is an order of magnitude lower. This can be attributed to the fact that the conductivity measurements ${ }^{21}$ were performed on pellets containing $\mathrm{LiLa}\left(\mathrm{BH}_{4}\right)_{3} \mathrm{Cl}$ and nonconducting $\mathrm{LiCl}$, so that the theoretical carrier density could not be reached.

As a final remark, we would like to note that the results of our limited NMR measurements for the related Ce-based compound $\mathrm{LiCe}\left(\mathrm{BH}_{4}\right)_{3} \mathrm{Cl}$ are also consistent with high diffusive mobility of $\mathrm{Li}$ ions in this compound. In particular, the drop of the measured ${ }^{7} \mathrm{Li}$ NMR line width in $\mathrm{LiCe}\left(\mathrm{BH}_{4}\right)_{3} \mathrm{Cl}$ (Figure S1 of the Supporting Information) occurs at nearly the same temperatures as in $\mathrm{LiLa}\left(\mathrm{BH}_{4}\right)_{3} \mathrm{Cl}$. However, a full characterization of atomic motions in $\mathrm{LiCe}\left(\mathrm{BH}_{4}\right)_{3} \mathrm{Cl}$ using $\mathrm{NMR}$ has proved to be impossible because of the presence of localized electron spin moments on Ce. The measured proton spinlattice relaxation rate in $\mathrm{LiCe}\left(\mathrm{BH}_{4}\right)_{3} \mathrm{Cl}$ (Figure $\mathrm{S} 2$ of the Supporting Information) is dominated by the strong interaction between nuclear spins and these localized electron spin moments; this leads to very high proton spin-lattice relaxation rates without any peaks.

\section{CONCLUSIONS}

The analysis of the temperature and frequency dependences of the measured proton spin-lattice relaxation rate for LiLa$\left(\mathrm{BH}_{4}\right)_{3} \mathrm{Cl}$ has revealed a very fast reorientational motion of $\mathrm{BH}_{4}$ groups in this compound. The most probable value of the jump rate for this fast reorientational process is found to reach $\sim 10^{8}$ $\mathrm{s}^{-1}$ at $58 \mathrm{~K}$. Our ${ }^{1} \mathrm{H}$ spin-lattice relaxation rate results in the low-temperature region are satisfactorily described by a twopeak distribution of the activation energies with the peak $E_{\text {a }}$ values of 41 and $50 \mathrm{meV}$. Above $200 \mathrm{~K}, \mathrm{BH}_{4}$ reorientations for this process become too fast to be probed by NMR. Our data in the high-temperature region are governed by another (slower) motional process giving rise to the sharp drop in the ${ }^{7} \mathrm{Li} \mathrm{NMR}$ line width near $220 \mathrm{~K}$ and to the ${ }^{1} \mathrm{H},{ }^{11} \mathrm{~B}$, and ${ }^{7} \mathrm{Li}$ spin-lattice relaxation rate peaks in the range $250-300 \mathrm{~K}$. While the behavior of the ${ }^{7} \mathrm{Li}$ NMR line width unambiguously indicates the onset of translational diffusion of $\mathrm{Li}$ ions, the amplitude of the observed high-temperature peak of the ${ }^{1} \mathrm{H}$ spin-lattice relaxation rate is found to be too high to result solely from $\mathrm{Li}$ diffusion. This means that the high-temperature relaxation rate peaks originate from a combined effect of two types of motion occurring at the same frequency scale: $\mathrm{Li}$ ion diffusion and a slower reorientational motion of $\mathrm{BH}_{4}$ groups. Such a result suggests that these two types of motion may be correlated, so that certain $\mathrm{BH}_{4}$ reorientations facilitate $\mathrm{Li}$ ion jumps. The 
estimates of the activation energy for $\mathrm{Li}$ diffusion and the tracer $\mathrm{Li}$ ion diffusion coefficient at room temperature give the values of $0.30 \mathrm{eV}$ and $5.2 \times 10^{-8} \mathrm{~cm}^{2} / \mathrm{s}$, respectively. These values indicate that $\mathrm{LiLa}\left(\mathrm{BH}_{4}\right)_{3} \mathrm{Cl}$ can be considered as a promising solid $\mathrm{Li}$ ion conductor.

\section{ASSOCIATED CONTENT}

\section{S Supporting Information}

Results of the ${ }^{7} \mathrm{Li}$ and ${ }^{1} \mathrm{H}$ NMR measurements for the related Ce-based compound $\mathrm{LiCe}\left(\mathrm{BH}_{4}\right)_{3} \mathrm{Cl}$. This material is available free of charge via the Internet at http://pubs.acs.org.

\section{AUTHOR INFORMATION}

\section{Corresponding Author}

*E-mail: skripov@imp.uran.ru. Fax: +7-343-374-5244.

\section{Notes}

The authors declare no competing financial interest.

\section{ACKNOWLEDGMENTS}

This work was partially supported by the Russian Foundation for Basic Research (Grant No. 12-03-00078) and by the Priority Program "Physico-technical principles of development of technologies and devices for smart adaptive electrical networks" of the Russian Academy of Sciences. The authors also acknowledge funding from the European Community's Seventh Framework Program FP7/2007-2013 under The Fuel Cells and Hydrogen Joint Undertaking (FCH JU), project BOR4STORE (303428), the Danish National Research Foundation, Center for Materials Crystallography (DNRF93), the Danish Strategic Research Council (The HyFillFast project), and the Carlsberg Foundation.

\section{REFERENCES}

(1) Fichtner, M. Conversion Materials for Hydrogen Storage and Electrochemical Applications-Concepts and Similarities. J. Alloys Compd. 2011, 509S, S529-S534.

(2) Orimo, S.; Nakamori, Y.; Elisen, J. R.; Züttel, A.; Jensen, C. M. Complex Hydrides for Hydrogen Storage. Chem. Rev. 2007, 107, 4111-4132.

(3) Li, H. W.; Yan, Y.; Orimo, S.; Züttel, A.; Jensen, C. M. Recent Progress in Metal Borohydrides for Hydrogen Storage. Energies 2011, $4,185-214$.

(4) Rude, L. H.; Nielsen, T. K.; Ravnsbæk, D. B.; Bösenberg, U.; Ley, M. B.; Richter, B.; Arnbjerg, L. M.; Dornheim, M.; Filinchuk, Y.; Besenbacher, F.; et al. Tailoring Properties of Borohydrides for Hydrogen Storage: A Review. Phys. Status Solidi A 2011, 208, 17541773.

(5) Grochala, W.; Edwards, P. P. Thermal Decomposition of the Non-Interstitial Hydrides for the Storage and Production of Hydrogen. Chem. Rev. 2004, 104, 1283-1316.

(6) Ravnsbæk, D. B.; Filinchuk, Y.; Černý, R.; Jensen, T. R. Powder Diffraction Methods for Studies of Borohydride-Based Energy Storage Materials. Z. Kristallogr. 2010, 225, 557-569.

(7) Nakamori, Y.; Orimo, S. Destabilization of Li-Based Complex Hydrides. J. Alloys Compd. 2004, 370, 271-275.

(8) Vajo, J. J.; Mertens, F.; Ahn, C. C.; Bowman, R. C.; Fultz, B. Altering Hydrogen Storage Properties by Hydride Destabilization through Alloy Formation: $\mathrm{LiH}$ and $\mathrm{MgH}_{2}$ Destabilized with Si. J. Phys. Chem. B 2004, 108, 13977-13983.

(9) Vajo, J. J.; Olson, G. L. Hydrogen Storage in Destabilized Chemical Systems. Scr. Mater. 2007, 56, 829-834.

(10) Gross, A. V.; Vajo, J. J.; Atta, C. L. V.; Olson, G. L. Enhanced Hydrogen Storage Kinetics of $\mathrm{LiBH}_{4}$ in Nanoporous Carbon Scaffolds. J. Phys. Chem. C 2008, 112, 5651-5657.
(11) Nielsen, T. K.; Jensen, T. R.; Besenbacher, F. Nanoconfined Hydrides for Energy Storage. Nanoscale 2011, 3, 2086-2098.

(12) Huot, J.; Ravnsbæk, D. B.; Zhang, J.; Cuevas, F.; Latroche, M.; Jensen, T. R. Mechanochemical Synthesis of Hydrogen Storage Materials. Prog. Mater. Sci. 2013, 58, 30-75.

(13) Hagemann, H.; Longhini, M.; Kaminski, J. W.; Wesolowski, T. A.; Černý, R.; Penin, N.; Sørby, M. H.; Hauback, B. C.; Severa, G.; Jensen, C. M. $\mathrm{LiSc}\left(\mathrm{BH}_{4}\right)_{4}$ : A Novel Salt of $\mathrm{Li}^{+}$and Discrete $\mathrm{Sc}\left(\mathrm{BH}_{4}\right)_{4}{ }^{-}$ Complex Anions. J. Phys. Chem. A 2008, 112, 7551-7555.

(14) Kim, C.; Hwang, S. J.; Bowman, R. C.; Reiter, J. W.; Zan, J. A.; Kulleck, J. G.; Kabbour, H.; Majzoub, E. H.; Ozolins, V. $\mathrm{LiSc}\left(\mathrm{BH}_{4}\right)_{4}$ as a Hydrogen Storage Material: Multinuclear High-Resolution SolidState NMR and First-Principles Density Functional Theory Studies. J. Phys. Chem. C 2009, 113, 9956-9968.

(15) Černý, R.; Severa, G.; Ravnsbæk, D. B.; Filinchuk, Y.; d'Anna, V.; Hagemann, H.; Haase, D.; Jensen, C. M.; Jensen, T. R. $\mathrm{NaSc}\left(\mathrm{BH}_{4}\right)_{4}$ : A Novel Scandium-Based Borohydride. J. Phys. Chem. C 2010, 114, 1357-1364.

(16) Černý, R.; Ravnsbæk, D. B.; Severa, G.; Filinchuk, Y.; d'Anna, V.; Hagemann, H.; Haase, D.; Skibsted, J.; Jensen, C. M.; Jensen, T. R. Structure and Characterization of $\mathrm{KSc}\left(\mathrm{BH}_{4}\right)_{4}$. J. Phys. Chem. C 2010, 114, 19540-19549.

(17) Jaroń, T.; Grochala, W. Probing Lewis Acidity of $\mathrm{Y}\left(\mathrm{BH}_{4}\right)_{3}$ via Its Reactions with $\mathrm{MBH}_{4}\left(\mathrm{M}=\mathrm{Li}, \mathrm{Na}, \mathrm{K}, \mathrm{NMe}_{4}\right)$. Dalton Trans. 2011, 40, 12808-12817.

(18) Ravnsbæk, D. B.; Ley, M. B.; Lee, Y. S.; Hagemann, H.; D’Anna, V.; Cho, Y. W.; Filinchuk, Y.; Jensen, T. R. A Mixed-Cation MixedAnion Borohydride $\mathrm{NaY}\left(\mathrm{BH}_{4}\right)_{2} \mathrm{Cl}_{2}$. Int. J. Hydrogen Energy 2012, 37, $8428-8438$

(19) Frommen, C.; Sørby, M. H.; Ravindran, P.; Vajeeston, P.; Fjellvåg, H.; Hauback, B. C. Synthesis, Crystal Structure, and Thermal Properties of the First Mixed-Metal and Anion-Substituted Rare Earth Borohydride $\mathrm{LiCe}\left(\mathrm{BH}_{4}\right)_{3} \mathrm{Cl}$. J. Phys. Chem. C 2011, 115, 2359123602.

(20) Ley, M. B.; Ravnsbæk, D. B.; Filinchuk, Y.; Lee, Y. S.; Janot, R.; Cho, Y. W.; Skibsted, J.; Jensen, T. R. $\mathrm{LiCe}\left(\mathrm{BH}_{4}\right)_{3} \mathrm{Cl}$, a New LithiumIon Conductor and Hydrogen Storage Material with Isolated Tetranuclear Anionic Clusters. Chem. Mater. 2012, 24, 1654-1663.

(21) Ley, M. B.; Boulineau, S.; Janot, R.; Filinchuk, Y.; Jensen, T. R. New Li Ion Conductors and Solid State Hydrogen Storage Materials: $\operatorname{LiM}\left(\mathrm{BH}_{4}\right)_{3} \mathrm{Cl}, \mathrm{M}=\mathrm{La}$, Gd. J. Phys. Chem. C 2012, 116, 21267-21276.

(22) Matsuo, M.; Nakamori, Y.; Orimo, S.; Maekawa, H.; Takamura, H. Lithium Superionic Conduction in Lithium Borohydride Accompanied by Structural Transition. Appl. Phys. Lett. 2007, 91, 224103.

(23) Skripov, A. V.; Soloninin, A. V.; Filinchuk, Y.; Chernyshov, D. Nuclear Magnetic Resonance Study of the Rotational Motion and the Phase Transition in $\mathrm{LiBH}_{4}$. J. Phys. Chem. C 2008, 112, 18701-18705.

(24) Corey, R. L.; Shane, D. T.; Bowman, R. C.; Conradi, M. S. Atomic Motions in $\mathrm{LiBH}_{4}$ by NMR. J. Phys. Chem. C 2008, 112, 18706-18710.

(25) Soloninin, A. V.; Skripov, A. V.; Buzlukov, A. L.; Stepanov, A. P. Nuclear Magnetic Resonance Study of Li and H Diffusion in the HighTemperature Solid Phase of $\mathrm{LiBH}_{4}$. J. Solid State Chem. 2009, 182, 2357-2361.

(26) Babanova, O. A.; Soloninin, A. V.; Stepanov, A. P.; Skripov, A. V.; Filinchuk, Y. Structural and Dynamical Properties of $\mathrm{NaBH}_{4}$ and $\mathrm{KBH}_{4}$ : NMR and Synchrotron X-ray Diffraction Studies. J. Phys. Chem. C 2010, 114, 3712-3718.

(27) Shane, D. T.; Corey, R. L.; McIntosh, C.; Rayhel, L. H.; Bowman, R. C.; Vajo, J. J.; Gross, A. F.; Conradi, M. S. $\mathrm{LiBH}_{4}$ in Carbon Aerogel Nanoscaffolds: An NMR Study of Atomic Motions. J. Phys. Chem. C 2010, 114, 4008-4014.

(28) Verdal, N.; Hartman, M. R.; Jenkins, T.; DeVries, D. J.; Rush, J. J.; Udovic, T. J. Reorientational Dynamics of $\mathrm{NaBH}_{4}$ and $\mathrm{KBH}_{4} . \mathrm{J}$. Phys. Chem. C 2010, 114, 10027-10033.

(29) Remhof, A.; Łodziana, Z.; Martelli, P.; Friedrichs, O.; Züttel, A.; Skripov, A. V.; Embs, J. P.; Strässle, T. Rotational Motion of $\mathrm{BH}_{4}$ Units 
in $\mathrm{MBH}_{4}(\mathrm{M}=\mathrm{Li}, \mathrm{Na}, \mathrm{K})$ from Quasielastic Neutron Scattering and Density Functional Calculations. Phys. Rev. B 2010, 81, 214304.

(30) Epp, V.; Wilkening, M. Fast Li Diffusion in Crystalline $\mathrm{LiBH}_{4}$ Due to Reduced Dimensionality: Frequency-Dependent NMR Spectroscopy. Phys. Rev. B 2010, 82, 020301(R).

(31) Babanova, O. A.; Soloninin, A. V.; Skripov, A. V.; Ravnsbæk, D. B.; Jensen, T. R.; Filinchuk, Y. Reorientational Motion in Alkali-Metal Borohydrides: NMR Data for $\mathrm{RbBH}_{4}$ and $\mathrm{CsBH}_{4}$ and Systematics of the Activation Energy Variations. J. Phys. Chem. C 2011, 115, 1030510309.

(32) Verdal, N.; Udovic, T. J.; Rush, J. J. The Nature of $\mathrm{BH}_{4}$ Reorientations in Hexagonal $\mathrm{LiBH}_{4}$. J. Phys. Chem. C 2012, 116, 1614-1618.

(33) Jimura, K.; Hayashi, S. Reorientational Motion of $\mathrm{BH}_{4}$ Ions in Alkali Borohydrides $\mathrm{MBH}_{4}(\mathrm{M}=\mathrm{Li}, \mathrm{Na}, \mathrm{K})$ As Studied by Solid-State NMR. J. Phys. Chem. C 2012, 116, 4883-4891.

(34) Skripov, A. V.; Soloninin, A. V.; Babanova, O. A.; Hagemann, H.; Filinchuk, Y. Nuclear Magnetic Resonance Study of Reorientational Motion in $\alpha-\mathrm{Mg}\left(\mathrm{BH}_{4}\right)_{2}$. J. Phys. Chem. C 2010, 114, 1237012374 .

(35) Blanchard, D.; Riktor, M. D.; Maronsson, J. B.; Jacobsen, H. S.; Kehres, J.; Sveinbjörnsson, D.; Bardaji, E. G.; Léon, A.; Juranyi, F.; Wuttke, J.; et al. Hydrogen Rotational and Translational Diffusion in Calcium Borohydride from Quasielastic Neutron Scattering and DFT Calculations. J. Phys. Chem. C 2010, 114, 20249-20257.

(36) Shane, D. T.; Rayhel, L. H.; Huang, Z.; Zhao, J. C.; Tang, X.; Stavila, V.; Conradi, M. S. Comprehensive NMR Study of Magnesium Borohydride. J. Phys. Chem. C 2011, 115, 3172-3177.

(37) Blanchard, D.; Maronsson, J. B.; Riktor, M. D.; Kheres, J.; Sveinbjörnsson, D.; Bardaji, E. G.; Léon, A.; Juranyi, F.; Wuttke, J.; Lefmann, K.; et al. Hindered Rotational Energy Barriers of $\mathrm{BH}_{4}$ Tetrahedra in $\beta-\mathrm{Mg}\left(\mathrm{BH}_{4}\right)_{2}$ from Quasielastic Neutron Scattering and DFT Calculations. J. Phys. Chem. C 2012, 116, 2013-2023.

(38) Soloninin, A. V.; Babanova, O. A.; Skripov, A. V.; Hagemann, H.; Richter, B.; Jensen, T. R.; Filinchuk, Y. NMR Study of Reorientational Motion in Alkaline-Earth Borohydrides: $\beta$ and $\gamma$ Phases of $\mathrm{Mg}\left(\mathrm{BH}_{4}\right)_{2}$ and $\alpha$ and $\beta$ Phases of $\mathrm{Ca}\left(\mathrm{BH}_{4}\right)_{2}$. J. Phys. Chem. C 2012, 116, 4913-4920.

(39) Eagles, M.; Sun, B.; Richter, B.; Jensen, T. R.; Filinchuk, Y.; Conradi, M. S. NMR Investigation of Nanoporous $\gamma-\mathrm{Mg}\left(\mathrm{BH}_{4}\right)_{2}$ and Its Thermally Induced Phase Changes. J. Phys. Chem. C 2012, 116, 13033-13037.

(40) Soloninin, A. V.; Skripov, A. V.; Yan, Y.; Remhof, A. Nuclear Magnetic Resonance Study of Hydrogen Dynamics in $\mathrm{Y}\left(\mathrm{BH}_{4}\right)_{3}$. J. Alloys Compd. 2013, 555, 209-212.

(41) Maekawa, H.; Matsuo, M.; Takamura, H.; Ando, M.; Noda, Y.; Karahashi, T.; Orimo, S. Halide-Stabilized $\mathrm{LiBH}_{4}$, a Room-Temperature Lithium Fast-Ion Conductor. J. Am. Chem. Soc. 2009, 131, 894895.

(42) Martelli, P.; Remhof, A.; Borgschulte, A.; Ackermann, R.; Strässle, T.; Embs, J. P.; Ernst, M.; Matsuo, M.; Orimo, S.; Züttel, A. Rotational Motion in $\mathrm{LiBH}_{4} / \mathrm{LiI}$ Solid Solutions. J. Phys. Chem. A 2011, 115, 5329-5334.

(43) Skripov, A. V.; Soloninin, A. V.; Rude, L. H.; Jensen, T. R.; Filinchuk, Y. Nuclear Magnetic Resonance Studies of Reorientational Motion and Li Diffusion in $\mathrm{LiBH}_{4}-\mathrm{LiI}$ Solid Solutions. J. Phys. Chem. C 2012, 116, 26177-26184.

(44) Verdal, N.; Udovic, T. J.; Rush, J. J.; Wu, H.; Skripov, A. V. Evolution of the Reorientational Motions of the Tetrahydroborate Anions in Hexagonal $\mathrm{LiBH}_{4}-\mathrm{LiI}$ Solid Solution by High- $Q$ Quasielastic Neutron Scattering. J. Phys. Chem. C 2013, 117, 12010-12018.

(45) Abragam, A. The Principles of Nuclear Magnetism; Clarendon Press: Oxford, U.K., 1961.

(46) Markert, J. T.; Cotts, E. J.; Cotts, R. M. Hydrogen Diffusion in the Metallic Glass $a-\mathrm{Zr}_{3} \mathrm{RhH}_{3.5}$. Phys. Rev. B 1988, 37, 6446-6452.

(47) Witschas, M.; Eckert, H.; Wilmer, D.; Banhatti, R. D.; Funke, K.; Fitter, J.; Lechner, R. E.; Korus, G.; Jansen, M. Anion Rotation and Cation Transport in the Rotor Phase $\alpha$-Sodium Orthophosphate:
Paddle-Wheel Mechanism Redefined in View of New Experimental Results. Z. Phys. Chem. 2000, 214, 643-673.

(48) Witschas, M.; Eckert, H.; Freiheit, H.; Putnis, A.; Korus, G.; Jansen, M. Anion Rotation and Cation Diffusion in Low-Temperature Sodium Orthophosphate: Results from Solid-State NMR. J. Phys. Chem. A 2001, 105, 6808-6816.

(49) Meyer, H.-W.; Jurányi, F.; Wilmer, D. Coupled Anion and Cation Dynamics of Silver Orthophosphate in the Picosecond Range. Solid State Ionics 2006, 177, 3045-3049.

(50) Wilkening, M.; Gebauer, D.; Heitjans, P. Diffusion Parameters in Single-Crystalline $\mathrm{Li}_{3} \mathrm{~N}$ As Probed by ${ }^{6} \mathrm{Li}$ and ${ }^{7} \mathrm{Li}$ Spin-Alignment Echo NMR Spectroscopy in Comparison with Results from ${ }^{8} \mathrm{Li} \beta$ Radiation Detected NMR. J. Phys.: Condens. Matter 2008, 20, 022201.

(51) Heitjans, P.; Schirmer, A.; Indris, S. NMR and $\beta$-NMR Studies of Diffusion in Interface-Dominated and Disordered Solids. In Diffusion in Condensed Matter-Methods, Materials, Models; Heitjans, P., Kärger, J., Eds.; Springer: Berlin, Germany, 2005; pp 367-415.

(52) Fukai, Y. The Metal-Hydrogen System, Springer: Berlin, Germany, 1993.

(53) Kamaya, N.; Homma, K.; Yamakawa, Y.; Hirayama, M.; Kanno, R.; Yonemura, M.; Kamiyama, T.; Kato, Y.; Hama, S.; Kawamoto, K.; et al. A Lithium Superionic Conductor. Nat. Mater. 2011, 10, 682686. 